\title{
PREDICTION OF DRUG SENSITIVITY IN INDIVIDUALS WITH ATYPICAL SERUM CHOLINESTERASE BASED ON IN VITRO BIOCHEMICAL STUDIES*
}

\author{
Rita J. Valentino, $†$ Oksana Lockridge $\$$ Harry W. Eckerson and Bert N. La Du \\ Pharmacology Department, University of Michigan Medical School, Ann Arbor, MI 48109, U.S.A.
}

(Received 8 September 1980; accepted 16 December 1980)

\begin{abstract}
V_{\max }$ and $K_{m}$ values with twenty-five "atypical" and thirty-seven "usual" cholinesterase human sera were determined for the cholinesterase substrates procaine, tetracaine, benzoylcholine, $o$-nitrophenylbutyrate, $\alpha$-naphthylacetate and aspirin. Aspirin was demonstrated to be a substrate for serum cholinesterase. For each of these substrates the ratio of $V_{\max }$ substrate to $V_{\max }$ benzoylcholine was found to be similar with atypical and usual cholinesterase sera. Therefore, we concluded that the respective turnover numbers for atypical and usual cholinesterase were the same. Both atypical and usual cholinesterase sera had turnover numbers of $255 \mathrm{~min}^{-1}$ for procaine, $74 \mathrm{~min}^{-1}$ for tetracaine, $7200 \mathrm{~min}^{-1}$ for aspirin in the presence of $50 \mathrm{mM} \mathrm{CaCl}, 36,000 \mathrm{~min}^{-1}$ for $\alpha$-naphthylacetate, and $48,000 \mathrm{~min}^{-1}$ for 0 -nitrophenylbutyrate, at $25^{\circ}$ in $0.1 \mathrm{M}$ Tris-Cl buffer, $\mathrm{pH} 7.4$. A comparison of $K_{m}$ values for atypical and usual cholinesterase indicated that the positively charged substrates, as well as aspirin in the presence of $\mathrm{CaCl}_{2}$, showed a lower affinity with atypical than with usual cholinesterase, while neutral esters had nearly the same $K_{m}$ for atypical and usual cholinesterase. These results imply that individuals with atypical cholinesterase will hydrolyze therapeutic doses of positively charged substrates and aspirin at reduced rates, but neutral substrates should be hydrolyzed at normal rates.
\end{abstract}

The clinical importance of serum cholinesterase (EC 3.1.1.8; acylcholine acyl-hydrolase; also known as pseudocholinesterase and butyrylcholinesterase) was first recognized when certain patients developed respiratory paralysis for several hours after receiving normal doses of succinylcholine. These patients hydrolyzed the drug very slowly because they had inherited an "atypical" cholinesterase, which has a much lower affinity for succinylcholine, than does "usual" cholinesterase $[1,2]$. Based upon this pharmacogenetic explanation for succinylcholine sensitivity, one might predict that individuals with atypical cholinesterase would also show considerable reduction in the rates of hydrolysis of other drugs known to be substrates for the enzyme. For example, Kalow [3] as well as Foldes et al. [4] have suggested that atypical cholinesterase patients might be more susceptible to certain local anesthetics.

In the present report the possibility of increased drug sensitivity of individuals with atypical cholinesterase was investigated by means of in vitro biochemical studies. Sera from patients with atypical

* Supported by a Horace H. Rackham predoctoral fellowship to R. J. V.; by U.S. Public Health Service Grants NS 15871 and GM 27028; and by a grant from the Hoffmann-La Roche Foundation.

† Present address: Pharmacology Department, University of North Carolina Medical School, Chapel Hill, NC 27514, U.S.A.

¥ Address correspondence to: Oksana Lockridge, Pharmacology Department, Medical Science I, Room M6323, University of Michigan, Ann Arbor, MI 48109, U.S.A. cholinesterase, as well as from normal individuals, were characterized with respect to their affinities ( $K_{m}$ values) and maximum velocities of enzymatic hydrolysis ( $V_{\max }$ values) with various ester substrates. The compounds selected for study are known to be substrates of cholinesterase in human serum, and no other esterase in human serum contributes significantly to their hydrolysis [5-8]. The substrates were classified according to their net charge at $\mathrm{pH} 7.4$, and it was found that neutral compounds were distinguished as a group from all other substrates, in that only neutral compounds had the same $K_{m}$ value for both atypical and usual cholinesterases.

\section{METHODS}

Cholinesterase. Frozen sera from thirty-seven people of the "usual" cholinesterase genotype and twenty-five people of the "atypical" cholinesterase genotype were used for these studies. The samples were selected to give a broad range of activities and, therefore, do not represent the average activity level in each population. Cholinesterase genotype was assigned on the basis of the characteristic dibucaine number [1], fluoride number [9], and activity with benzoylcholine [10].

Activity assays. All assays were carried out in a recording spectrophotometer (the Gilford 2000 or Beckman DBG) whose cuvette compartment was maintained at $25^{\circ}$. The buffer for activity assays with benzoylcholine was $0.067 \mathrm{M}$ phosphate, $\mathrm{pH} 7.4$; the buffer for all other substrates was $0.10 \mathrm{M}$ Tris- $\mathrm{Cl}$, $\mathrm{pH}$ 7.4. All chemicals were from the Sigma Chemical Co., St. Louis, MO, except aspirin which was from the Mallinckrodt Chemical Works, St. Louis, MO. 
Benzoylcholine $\mathrm{HCl}$ hydrolysis was measured at $240 \mathrm{~nm}\left(\Delta \varepsilon=6700 \mathrm{M}^{-1} \mathrm{~cm}^{-1}\right)$ by the method of Kalow and Lindsay [10], over the range 12.5 to $50 \mu \mathrm{M}$; serum dilution in the assays was $1: 100, o$ Nitrophenylbutyrate was dissolved in methanol, and a stock solution of $1.0 \mathrm{mM}$ was prepared according to the method of Huggins and Lapides [11]. Production of $o$-nitrophenol was followed at $410 \mathrm{~nm}$ $\left(\varepsilon=2970 \mathrm{M}^{-1} \mathrm{~cm}^{-1}\right)$; the serum dilution in the assays was $1: 300$. The concentrations of $o$-nitrophenylbutyrate ranged from 0.08 to $0.80 \mathrm{mM}$. Hydrolysis of procaine $\mathrm{HCl}$ was observed at $305 \mathrm{~nm}$ $\left(\varepsilon=12,200 \mathrm{M}^{-1} \mathrm{~cm}^{-1}\right)$ and hydrolysis of tetracaine $\mathrm{HCl}$ at $325 \mathrm{~nm}\left(\varepsilon=13,500 \mathrm{M}^{-1} \mathrm{~cm}^{-1}\right)$; serum dilution was $1: 30$. For assays with atypical cholinesterase, the procaine concentrations ranged from 20 to $100 \mu \mathrm{M}$, and the tetracaine concentrations from 6.25 to $50 \mu \mathrm{M}$. For assays with usual cholinesterase, the procaine concentrations ranged from 2.5 to $6.7 \mu \mathrm{M}$, and the tetracaine concentrations from 0.17 to $1.0 \mu \mathrm{M}$. Aspirin (acetylsalicylic acid) hydrolysis was measured at $300 \mathrm{~nm}\left(\varepsilon=3500 \mathrm{M}^{-1} \mathrm{~cm}^{-1}\right)$ in the presence of $50 \mathrm{mM}$ calcium chloride, over the range 4 to $31 \mathrm{mM}$; serum dilution in the assays was $1: 15$. A stock solution of $50 \mathrm{mM}$ aspirin at $\mathrm{pH} 7.4$ was prepared by adding an equivalent amount of $\mathrm{NaOH}$ in a dropwise manner to a rapidly stirring mixture of aspirin and buffer. Only freshly prepared (no more than 20 min old) aspirin solutions were used because aspirin rapidly decomposed in solution, and its product, salicylate, interfered with the rate assays due to its high u.v. absorbance. The use of older aspirin solutions gave artifically slow rates of hydrolysis. The spontaneous rate of aspirin hydrolysis was subtracted from the rate observed in the presence of enzyme. $\alpha$-Naphthylacetate hydrolysis was monitored at $321 \mathrm{~nm}\left(\varepsilon=2220 \mathrm{M}^{-1} \mathrm{~cm}^{-1}\right)$ over the range 0.25 to $1.0 \mathrm{mM}$; all assays contained $6.6 \%$ ethanol and a serum dilution of $1: 30$. The procedure was essentially the same as that of Zapf and Coghlan [12] except that we measured initial rates.

\section{RESULTS}

Hydrolysis of aspirin. Hofstee [5] reported in 1951 that human serum cholinesterase hydrolyzed aspirin. Hofstee worked with serum and not with pure enzyme. The evidence identifying the enzyme as cholinesterase was its inhibition by $10^{-5} \mathrm{M}$ eserine, by organophosphates, and by acetylcholine. In our present work, prior to measuring rates of aspirin hydrolysis by serum, we determined that pure cholinesterase, prepared as described $[13,14]$, hydrolyzed aspirin. We also compared the rates of aspirin hydrolysis by pure cholinesterase and by serum and found that cholinesterase accounted for at least 90 per cent of the enzymatic degradation of aspirin by serum. Thus we have provided new evidence identifying cholinesterase as "aspirinase". A separate manuscript on aspirin hydrolysis is in preparation.

Maximum rates of substrate hydrolysis by atypical and usual cholinesterase. The maximum velocity of substrate hydrolysis, $V_{\max }$, was determined for each compound from a Lineweaver-Burk plot for each individual serum sample. The observed maximum velocities of hydrolysis of benzoylcholine by the usual and atypical cholinesterases were correlated with the $V_{\max }$ value when procaine, tetracaine, $o$-nitrophenylbutyrate, $\alpha$-naphthylacetate or aspirin was the substrate (Fig. 1). The slopes of the lines relating the $V_{\max }$ for benzoylcholine hydrolysis to the $V_{\max }$ values for hydrolysis of the other substrates were not significantly different for the atypical and the usual cholinesterases (at the $\mathrm{P}<0.05$ level) as shown in

Table 1. Regression analysis of the data in Fig. 1

\begin{tabular}{|c|c|c|c|c|}
\hline Substrate & $\begin{array}{l}\text { Cholinesterase } \\
\text { genotype* }\end{array}$ & $\mathbf{N}$ & Slope $\uparrow(r)$ & $t$-Statistic $\ddagger$ \\
\hline \multirow[t]{3}{*}{ Procaine } & AA & 12 & $0.0088(0.80)$ & \multirow[t]{3}{*}{1.44} \\
\hline & UU & 18 & $0.013(0.86)$ & \\
\hline & AA \& UU pooled & 30 & $0.017(0.95)$ & \\
\hline \multirow[t]{3}{*}{ Tetracaine } & $\mathrm{AA}$ & 12 & $0.0052(0.73)$ & \multirow[t]{3}{*}{0.565} \\
\hline & UU & 19 & $0.0065(0.78)$ & \\
\hline & AA \& UU pooled & 31 & $0.0049(0.86)$ & \\
\hline \multirow[t]{3}{*}{$o$-Nitrophenylbutyrate } & $\mathbf{A A}$ & 10 & $3.4(0.67)$ & \multirow[t]{3}{*}{0.20} \\
\hline & UU & 15 & $3.7(0.95)$ & \\
\hline & AA \& UU pooled & 25 & $3.2(0.86)$ & \\
\hline \multirow[t]{3}{*}{$\alpha$-Naphthylacetate } & AA & 10 & $3.1(0.94)$ & \multirow[t]{3}{*}{1.35} \\
\hline & UU & 14 & $2.2(0.90)$ & \\
\hline & AA \& UU pooled & 24 & $2.4(0.92)$ & \\
\hline \multirow[t]{3}{*}{ Aspirin } & AA & 6 & $0.54(0.95)$ & \multirow[t]{3}{*}{0.63} \\
\hline & UU & 8 & $0.46(0.96)$ & \\
\hline & AA \& UU pooled & 14 & $0.48(0.86)$ & \\
\hline
\end{tabular}

* Atypical cholinesterase genotype is designated AA; the usual is UU. Atypicals and usuals were treated as one group in "AA \& UU pooled".

† The slope and correlation coefficient $(r)$ were determined by linear regression using the $V_{\max }$ for benzoylcholine hydrolysis as the independent variable and the $V_{\max }$ value with the other substrate as the dependent variable. The units of slope are $\mu$ moles of substrate hydrolyzed, at the $V_{\max }$, per min per ml divided by the $\mu$ moles of benzoylcholine hydrolyzed, at the $V_{\max }$, per min per ml.

$\ddagger A$ test for non-parallelism of the slopes of the atypical versus the usual cholinesterase was done by calculation of a $t$-statistic. None of the $t$ values found was significant at the $\mathrm{P}<0.05$ level for degrees of freedom $=n_{1}+n_{2}-4$. 

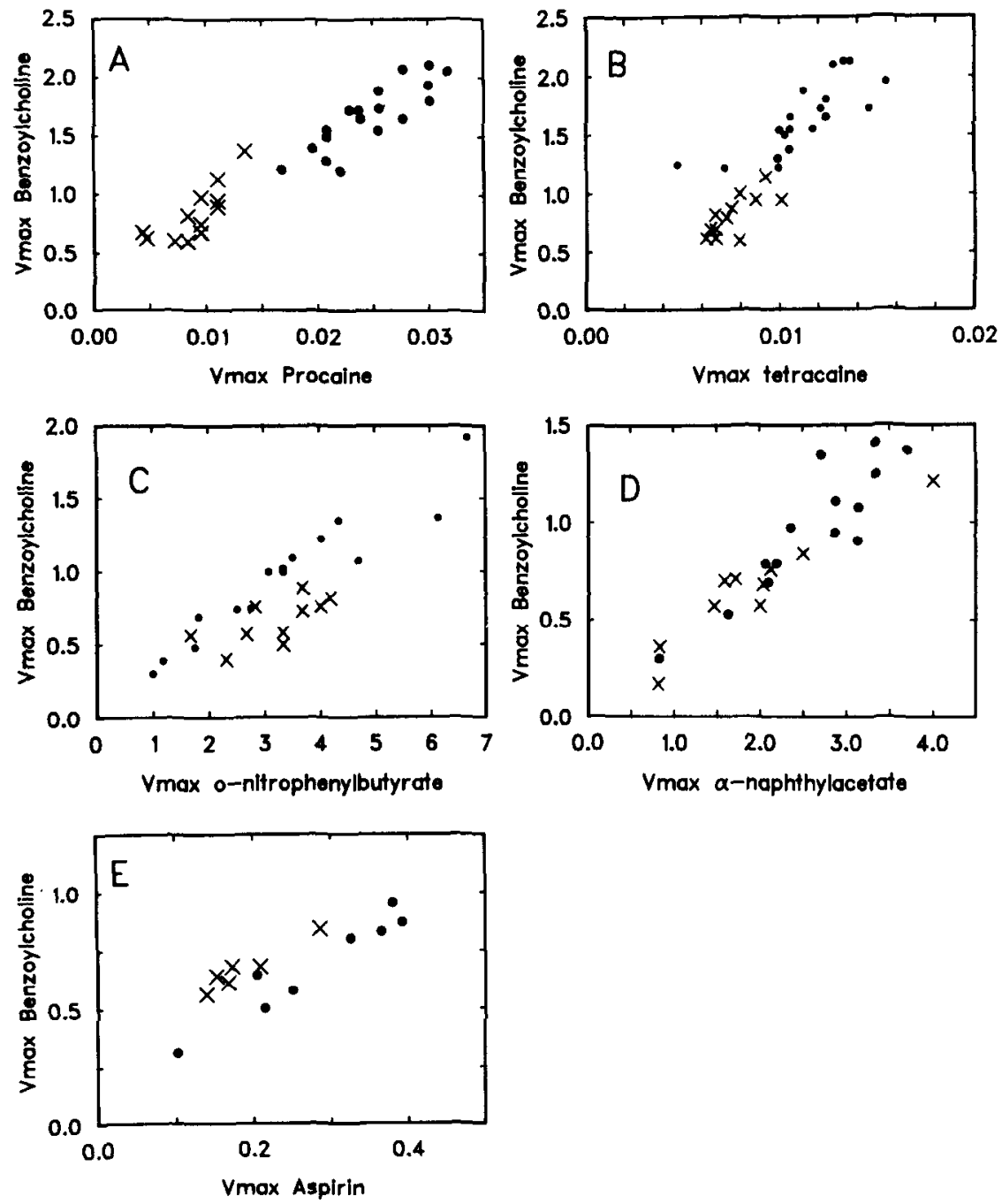

Fig. 1. Maximum rates of substrate hydrolysis by atypical and usual cholinesterase sera. Each point represents one serum sample. Key: (X) atypical cholinesterase; and (O) usual cholinesterase. $V_{\max }$ was determined for each compound from a Lineweaver-Burk plot for each serum sample. $V_{\max }$ is expressed as $\mu$ moles $\cdot \min ^{-1} \cdot(\mathrm{ml} \text { serum })^{-1}$. The set of serum samples is different in each graph.

Table 1. Thus, the relationship between the $V_{\max }$ for benzoylcholine hydrolysis and the $V_{\max }$ for hydrolysis of the other substrates was similar for both atypical and usual cholinesterases. Atypical and usual cholinesterase were treated as one group in order to estimate best the relationship between $V_{\max }$ for benzoylcholine hydrolysis and that for hydrolysis of the other substrates; this pooled value for slope is also shown in Table 1 . The turnover numbers for these substrates were calculated from the "AA \& UU pooled" slopes in Table 1 and are listed in Table 2 . Since the slopes of the lines for the atypical and usual cholinesterases were not significantly different, it may be concluded that the turnover number for atypical cholinesterase was the same as the turnover number for usual cholinesterase for each of these substrates; that is, the moles of substrate hydrolyzed per min per mole active site, measured under conditions where the substrate was saturating, was the same for the atypical and the usual cholinesterases.

$\mathrm{K}_{\mathrm{m}}$ values. A comparison of $K_{m}$ values of atypical and usual cholinesterase (Table 2) demonstrated that atypical cholinesterase had a higher $K_{m}$ than the usual cholinesterase for positively charged substrates (quaternary and tertiary amines). Likewise, atypical cholinesterase had a higher $K_{m}$ for aspirin; a negatively charged substrate, in the presence of $50 \mathrm{mM} \mathrm{CaCl}$. It is likely that aspirin forms a complex with calcium, having a net positive charge. In contrast, atypical and usual cholinesterases had nearly identical $K_{m}$ values for neutral substrates. Thus, atypical cholinesterase had a lower affinity for benzoylcholine, succinyldithiocholine, heroin, procaine, tetracaine, and aspirin complexed with $\mathrm{CaCl}_{2}$, than did usual cholinesterase.

This pattern of $K_{m}$ values was disturbed by $\alpha$ naphthylacetate. In the absence of added calcium, atypical cholinesterase had a $K_{m}$ of $0.37 \mathrm{mM}$ for this substrate, whereas usual cholinesterase had a $K_{m}$ of $1.0 \mathrm{mM}$, which is two and one-half times higher. This result confirms a similar observation reported by Bamford and Harris [8]. The $K_{m}$ values, however, 
are nearly identical for both enzyme genotypes in the presence of $20 \mathrm{mM}$ calcium chloride.

Calcium chloride stimulation. Figure 2 shows that $20 \mathrm{mM} \mathrm{CaCl}_{2}$ stimulated the observed rate of $\alpha$ naphthylacetate hydrolysis by usual cholinesterase at all $\alpha$-naphthylacetate concentrations tested. The extrapolated $V_{\max }$ rate, however, was the same with or without calcium chloride. Thus, calcium chloride affected the $K_{m}$, but not the $V_{\max }$, for usual cholinesterase when the substrate was $\alpha$-naphthylacetate. In contrast, the activity of atypical cholinesterase with $\alpha$-naphthylacetate was unaffected by the addition of calcium chloride, so that $K_{m}$ and $V_{\max }$ were the same whether activity was measured in $10 \mathrm{mM}$ EDTA or in $20 \mathrm{mM} \mathrm{CaCl} 2$.

Aspirin hydrolysis was also stimulated by calcium chloride. In contrast to the results with $\alpha$-naphthylacetate, calcium chloride stimulated the hydrolysis of this substance by both atypical and usual cholinesterases. The spontaneous rate of aspirin hydrolysis in 0.1 M Tris-Cl buffer, $\mathrm{pH} 7.4$, was not affected by $50 \mathrm{mM}$ calcium chloride.

Calcium chloride $(20 \mathrm{mM})$ also stimulated the hydrolysis of $o$-nitrophenylbutyrate, a neutral substrate, by usual cholinesterase (data not shown), but did not affect the rate of benzoylcholine hydrolysis in $0.1 \mathrm{M}$ Tris $\mathrm{Cl}$ buffer, $\mathrm{pH}$ 7.4.

Substrate inhibition. High concentrations of positively charged substrates, including benzoylcholine, procaine and tetracaine, inhibited the usual cholinesterase. The atypical cholinesterase, however, did not exhibit substrate inhibition. Thus, when the activities of atypical and usual cholinesterases were tested with $50 \mu \mathrm{M}$ tetracaine, the rate of hydrolysis by atypical cholinesterase was faster because, at this concentration of tetracaine, the usual cholinesterase was inhibited 55 per cent. At concentrations below $1 \mu \mathrm{M}$ tetracaine, the rate of hydrolysis by atypical cholinesterase was slower than by usual cholinesterase. This observation is consistent with the lower affinity $\left(K_{m}\right)$ of atypical cholinesterase for tetracaine.

No substrate inhibition was observed with the neutral coinpounds within the concentration range tested, a range that was limited by the relative insolubility of these compounds in aqueous buffers.

Comparison of atypical and usual cholinesterase activities measured at a single concentration of substrate. Figure 3 shows that atypical and usual sera fell into two distinct groups when activity with benzoylcholine was compared with activity with $o$-nitrophenylbutyrate. Atypical cholinesterase appeared to have more $o$-nitrophenylbutyrate activity per unit of benzoylcholine activity that did usual cholinesterase. This result agrees with a similar observation reported by McComb et al. [17]. Yet Fig. 1C shows that atypical and usual cholinesterase sera did not fall into two groups when activities were measured at $V_{\max }$. The discrepancy between the two comparisons exists because the $K_{m}$ for benzoylcholine was higher for atypical than for usual cholinesterase, whereas the $K_{m}$ for $o$-nitrophenylbutyrate was similar for both enzymes. Thus, when assays were done at one substrate concentration, as in Fig. 3, the atypical cholinesterase sera segregated into a group distinct from

Table 2. $K_{m}$ values and turnover numbers for various substrates of atypical and usual cholinesterase (ChE)

\begin{tabular}{|c|c|c|c|c|}
\hline \multirow[b]{2}{*}{ Substrate } & \multicolumn{2}{|c|}{$K_{m}{ }^{*}(\mathrm{mM})$} & \multirow{2}{*}{$\frac{V_{\max } \text { substrate } \dagger}{V_{\max } \text { benzoylcholine }}$} & \multirow{2}{*}{$\begin{array}{c}\text { Turnover } \\
\text { numbert } \\
\left(\mathrm{min}^{-1}\right)\end{array}$} \\
\hline & Usual ChE & Atypical ChE & & \\
\hline \multicolumn{5}{|l|}{ Quaternary amine esters } \\
\hline Benzoylcholine & 0.004 & 0.022 & 1.0 & 15,000 \\
\hline Succinyldithiocholine $\S$ & 0.035 & 1.08 & 0.0553 & 830 \\
\hline \multicolumn{5}{|l|}{ Tertiary amine esters } \\
\hline Heroin| & 0.11 & 0.45 & 0.0333 & 500 \\
\hline Procaine & 0.0066 & 0.10 & 0.017 & 255 \\
\hline Tetracaine & 0.00014 & 0.008 & 0.0049 & 74 \\
\hline \multicolumn{5}{|l|}{ Neutral esters } \\
\hline$o$-Nitrophenylbutyrate & 0.33 & 0.4 & 3.2 & 48,000 \\
\hline$\alpha$-Naphthylacetate & 1.0 & 0.37 & 2.4 & 36,000 \\
\hline $\begin{array}{c}\alpha \text {-Naphthylacetate }+ \\
20 \mathrm{mM} \mathrm{CaCl}_{2}\end{array}$ & 0.4 & 0.37 & 2.4 & 36,000 \\
\hline Negatively charged ester & & & & \\
\hline Aspirin $+50 \mathrm{mM} \mathrm{CaCl} 2$ & 4.2 & 16 & 0.48 & 7200 \\
\hline
\end{tabular}

${ }^{*} K_{m}$ and $V_{\max }$ values were determined from Lineweaver-Burk plots, using individual human sera. The buffer was $0.1 \mathrm{M}$ Tris- $\mathrm{Cl}$, $\mathrm{pH} 7.4,25^{\circ}$ for all substrates except benzoylcholine and heroin, which were assayed in $0.067 \mathrm{M}$ phosphate, $\mathrm{pH} 7.4$.

† The ratio $V_{\max }$ substrate $/ V_{\max }$ benzoylcholine is the slope for "AA \& UU pooled" from Table 1. The values for succinyldithiocholine and heroin are from Refs. 15 and 16 respectively.

$\$$ Turnover number was defined as moles substrate hydrolyzed per min per mole active site, at $V_{\max }$ conditions. Turnover number for benzoylcholine was determined by Lockridge and La Du [13] using highly purified usual and atypical cholinesterases. For all other substrates, turnover number was calculated by multiplying the benzoylcholine value of $15,000 \mathrm{~min}^{-1}$ times the ratio $V_{\max }$ substrate $/ V_{\max }$ benzoylcholine.

$\S$ From Hersh et al. [15].

|from Lockridge et al. [16]. Highly purified usual and atypical cholinesterases, rather than sera, were used. 

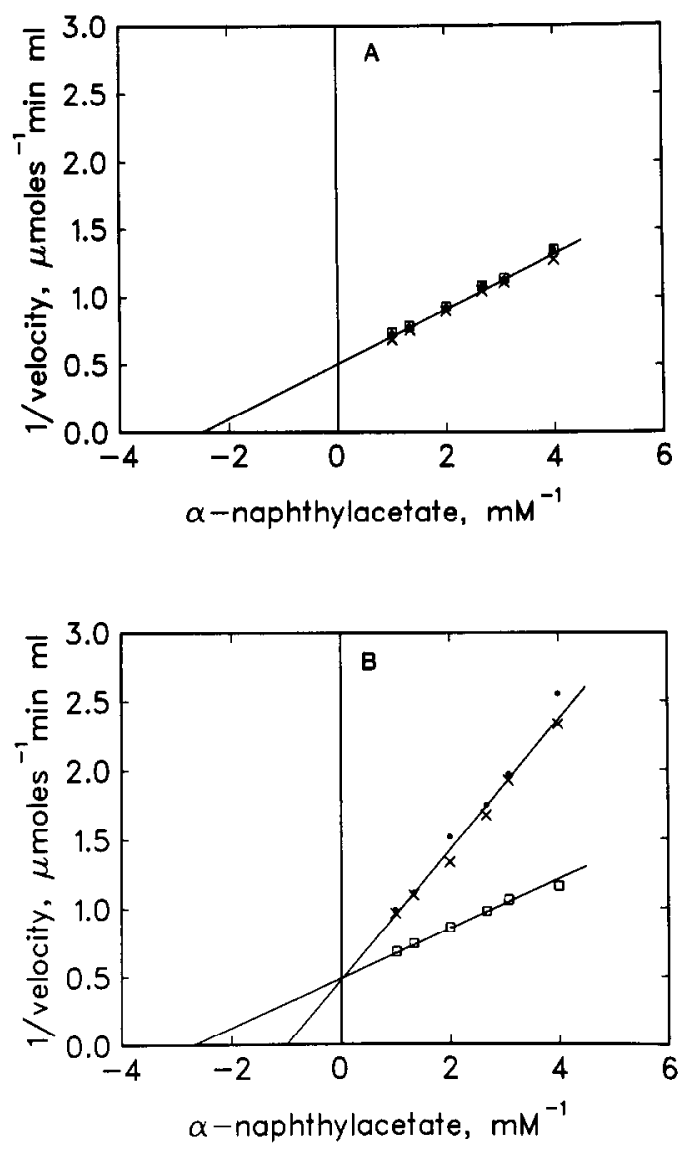

Fig. 2. Differential effect of calcium chloride on $\alpha$-naphthylacetate hydrolysis by atypical and usual cholinesterase sera. Panel A: Lineweaver-Burk plot showing the rates of hydrolysis of various concentrations of $\alpha$-naphthylacetate ( 1 to $0.25 \mathrm{mM}$ ) by one atypical cholinesterase serum, in the presence of $10 \mathrm{mM}$ EDTA (X), or $20 \mathrm{mM} \mathrm{CaCl}{ }_{2}$ (口), or with no addition (O). The buffer was $0.1 \mathrm{M}$ Tris-Cl, pH 7.4, at $25^{\circ}$. $K_{m}=0.42 \mathrm{mM} ; V_{\max }=$ $2.0 \mu$ moles $\cdot \min ^{-1} \cdot(\mathrm{ml} \text { serum })^{-1}$. Panel B: LineweaverBurk plot of the hydrolysis of $\alpha$-naphthylacetate by one usual cholinesterase serum, in the presence of $10 \mathrm{mM}$ EDTA (X) or with no addition (O). $K_{m}=1.0 \mathrm{mM}$; $V_{\max }=2.0 \mu$ moles $\cdot \min ^{-1} \cdot(\mathrm{ml} \text { serum })^{-1}$. In the presence of $20 \mathrm{mM} \mathrm{CaCl}$ (口), $K_{m}=0.38 \mathrm{mM}$, and $V_{\max }=$ $2.0 \mu \mathrm{moles} \cdot \mathrm{min}^{-1} \cdot(\mathrm{ml} \text { serum })^{-1}$. Twelve other sera (six atypical and six usual) were also tested and gave similar results. the usual sera. When $V_{\max }$ values were measured, however, the benzoylcholine activity of atypical cholinesterase increased to the level of usual cholinesterase, as shown in Fig. 1C.

Inhibition by tetramethylammonium chloride. Inhibition studies with tetramethylammonium were done to test the hypothesis that the major difference between the atypical and usual cholinesterase involved an alteration in the anionic binding site on the atypical cholinesterase $[2,13,18]$. The results are presented in Table 3 . When the substrate was positively charged (benzoylcholine and procaine), the positively charged inhibitor, tetramethylammonium chloride, was much more effective with usual than with atypical cholinesterase, as reflected by the ratio of $K_{i}$ values. When the substrate was a neutral ester (o-nitrophenylbutyrate and $\alpha$-naphthylacetate), tetramethylammonium chloride inhibited both usual and atypical cholinesterases with nearly the same potency - that is, the ratio of $K_{i}$ values was approximately 1 . With neutral substrates, inhibition by tetramethylammonium chloride appeared to be due to nonspecific ionic-strength effects, as indicated by the very high apparent $K_{i}$ values of 0.4 to $0.8 \mathrm{M}$, an interpretation supported by the observation of Huggins and Lapides [11] that $0.5 \mathrm{M} \mathrm{NaCl}$ inhibited p-nitrophenyl propionate hydrolysis by 70 per cent. Comparison of $K_{m}$ values (see Table 2) shows that the positively charged substrates, like the positively charged inhibitor, bound more tightly to usual cholinesterase than to atypical cholinesterase, whereas the neutral substrates bound with nearly the same affinity to both usual and atypical cholinesterase. These results are consistent with the conclusion that the anionic site was altered in atypical cholinesterase in such a way that it bound positively charged compounds poorly.

\section{DISCUSSION}

We are interested in defining the types of drugs that are likely to cause adverse reactions in individuals with atypical cholinesterase and the types that may have normal effects. We examined, therefore, the difference between atypical and usual cholinesterases, first, in their intrinsic abilities to hydrolyze substrates, a quality measured by the turnover number and, second, in their affinities for a series of esters, as measured by $K_{m}$.

Table 3. Tetramethylammonium chloride inhibition of hydrolysis of various substrates by usual and atypical cholinesterase (ChE) sera*

\begin{tabular}{lccc}
\hline & \multicolumn{2}{c}{ Apparent $K_{i}(\mathrm{M})$} & \\
Substrate & Atypical ChE & Usual ChE & $K_{i}$ ratio (A/U) \\
\hline $\begin{array}{l}\text { Positively charged esters } \\
\text { Benzoylcholine }\end{array}$ & 0.08 & 0.01 & \\
$\begin{array}{l}\text { Procaine } \\
\text { Neutral esters }\end{array}$ & 0.043 & $<0.01$ & 8.0 \\
$\begin{array}{l}o \text {-Nitrophenylbutyrate } \\
\text {-Naphthylacetate }\end{array}$ & 0.82 & 0.39 & $>4.3$ \\
\hline
\end{tabular}

* Tetramethylammonium chloride was used as an inhibitor at $0.1 \mathrm{M}, 0.25 \mathrm{M}$ and $0.5 \mathrm{M}$ in $0.1 \mathrm{M}$ Tris- $\mathrm{Cl}, \mathrm{pH}$ 7.4. The apparent $K_{i}$ values were evaluated from Dixon plots where the inhibition appeared to be competitive. 




Fig. 3. Comparison of atypical and usual cholinesterase activities measured at a single concentration of substrate. Activities of fourteen usual (O) and twelve atypical (X) cholinesterase sera were measured using $50 \mu \mathrm{M}$ benzoylcholine and $0.66 \mathrm{mM} o$-nitrophenylbutyrate. Activities are expressed as $\mu$ moles hydrolyzed $\cdot \mathrm{min}^{-1} \cdot(\mathrm{ml} \text { serum })^{-1}$.

We found that atypical and usual cholinesterases had the same turnover number with each of a variety of substrates, whether that substrate was positively charged, neutral, or negatively charged. Earlier studies by Lockridge and La Du [13] with three compounds had demonstrated that highly purified atypical and usual cholinesterases had identical turnover numbers. The present report, utilizing sera rather than purified enzymes, extends this conclusion to include several additional compounds. The values for the turnover numbers reported in Table 2 would not be correct if enzymes other than cholinesterase hydrolyzed these substrates in serum. Though the assumption has been made that cholinesterase is the only enzyme in serum that contributes significantly to hydrolysis of these substrates, there may be doubt regarding the validity of this assumption. Thus, the turnover values in Table 2 are not as reliable as turnover numbers measured with pure cholinesterase. The conclusion that atypical and usual cholinesterase have the same turnover number is independent of the actual value assigned to turnover number in Table 2, and it, therefore, does not rely on the validity of the above assumption. Furthermore, this conclusion is supported by a third line of evidence. We measured the cholinesterase protein concentration in twenty atypical sera and twenty-eight usual sera by immunological methods* and found that the turnover number for benzoylcholine and for $o$-nitrophenylbutyrate, when based on $\mu \mathrm{g}$ enzyme protein titrated with antibody, was the same for atypical and usual cholinesterase sera.

Since the turnover numbers of atypical and usual cholinesterase are the same, one can attribute a difference in $V_{\max }$ per $\mathrm{ml}$ serum to a difference in enzyme concentration; that is to say, a low $V_{\max }$ reflects a low enzyme concentration and a high $V_{\max }$ reflects a high cholinesterase concentration. $V_{\max }$ per

* H. W. Eckerson, A. Oseroff, O. Lockridge and B. N. La Du, unpublished results. $\mathrm{ml}$ serum was found by Bamford and Harris [8] and by Hersh et al. [15] to be similar, on the average, for sera containing atypical or usual cholinesterase. From their results we calculated that the concentration of atypical cholinesterase molecules in serum is about $75-85$ per cent of the concentration of usual cholinesterase molecules. Immunochemical titrations of atypical and usual cholinesterases in sera have led to a similar conclusion [19]. In our laboratory* immunodiffusion studies showed that sera classified as atypical had about 70 per cent of the cholinesterase concentration found in usual sera.

The $K_{m}$ values for all compounds, except aspirin, have been reported previously. Our values are similar to those of Davies et al. [20] for benzoylcholine, Kalow [6] and Foldes et al. [21] for procaine and tetracaine, Bamford and Harris [8] for $\alpha$-naphthylacetate, and McComb et al. [17] and Whittaker and Hardisty [22] for $o$-nitrophenylbutyrate, though strict comparisons cannot be made because buffer composition and temperature were, in many cases, different. Our observation that the affinities of atypical and usual cholinesterase are nearly identical for those substrates that are neutral esters provides an exception to the widely held generalization [20] that atypical cholinesterase has a lower affinity for all compounds.

That calcium chloride affects the $K_{m}$ for neutral compounds and for aspirin has not been reported previously, though Hofstce [5] did show that the rate of aspirin hydrolysis by human serum increased in the presence of $\mathrm{CaCl}_{2}$. The differential effect of $20 \mathrm{mM}$ calcium chloride on the hydrolysis of $\alpha$ naphthylacetate by atypical and usual cholinesterase can be used as another means of discriminating between the two genotypes.

The biochemical difference between atypical and usual cholinesterase may be a single amino acid mutation at the anionic site, as proposed by Kalow and Davies [2]. Muensch et al. [18] suggested that the mutation was from a negatively charged (Glu or Asp) to a positively charged residue (Arg or Lys). Our findings and those of Lockridge and $\mathrm{La} \mathrm{Du} \mathrm{[13]}$ agree with this hypothesis. That atypical and usual cholinesterase have the same turnover number and the same $K_{m}$ for neutral substrates but a different $K_{m}$ for positively charged substrates suggests that the esteratic sites are the same, but the anionic site is altered on atypical cholinesterase. Our tetramethylammonium chloride inhibition studies also support this conclusion.

The well-known succinylcholine sensitivity of atypical cholinesterase patients leads to a concern that these patients may also be sensitive to other drugs. Our results predict that neutral substrates of serum cholinesterase will be hydrolyzed nearly as rapidly in patients with atypical cholinesterase as in those with the usual type of enzyme. On the other hand, choline esters and their analogs-e.g. procaine and tetracaine, as well as aspirin-are expected to be hydrolyzed more slowly by patients with atypical cholinesterase because in vivo concentrations of drugs will be low and will, therefore, reflect the decreased binding affinity of atypical cholinesterase. This expectation has been substantiated by Raj et al. [23] who measured the level of chloroprocaine 
in the blood of patients after lumbar-epidural as well as brachial plexus blocks. The patient with atypical cholinesterase maintained high levels of chloroprocaine much longer than did other patients. However, this did not cause toxicity in the atypical cholinesterase patient, and the duration of block was not longer.

Tetracaine was reported by Smith and Foldes [24] to be hydrolyzed more rapidly, in vitro, by atypical than by usual cholinesterase $(0.23$ vs $0.20 \mu$ moles per hr per ml plasma). We have shown that this result is true only under the special circumstance of high tetracaine concentration $(50 \mu \mathrm{M})$ in which the usual cholinesterase undergoes marked substrate inhibition. Substrate inhibition was not observed with atypical cholinesterase. At low tetracaine concentrations, such as might be expected in therapeutic situations, the atypical cholinesterase hydrolyzes tetracaine more slowly due to its lower affinity for tetracaine.

Despite the theoretical possibility that the local anesthetics, including procaine and chloroprocaine, might cause toxicity in atypical cholinesterase individuals $[3,4]$, we know of only two reports linking atypical cholinesterase with toxicity to local anesthetics. In the report by Downs [25], the patient was assumed to have atypical cholinesterase because of a history of succinylcholine apnea. The atypical cholinesterase genotype, however, cannot be assigned with certainty on the basis of succinylcholine apnea, since only about 50 per cent of all apneic patients have atypical cholinesterase [26]. In the report by Zsigmond and Eilderton [27], the patients definitely had atypical cholinesterase, but the local anesthetics that caused toxicity were not identified. Thus, neither report firmly links atypical cholinesterase with toxicity to procaine or to any other ester-type local anesthetic.

\section{REFERENCES}

1. W. Kalow and K. Genest, Can. J. Biochem. Physiol. 35, 339 (1957).

2. W. Kalow and R. O. Davies, Biochem. Pharmac. 1, 183 (1958).
3. W. Kalow, Pharmacogenetics, Heredity and the Response to Drugs, p. 87. W. B. Saunders, Philadelphia (1962).

4. F. F. Foldes, V. M. Foldes, J. C. Smith and E. K. Zsigmond, Anesthesiology 24, 208 (1963).

5. B. H. J. Hofstee, Science 114, 128 (1951).

6. W. Kalow, J. Pharmac. exp. Ther. 104, 122 (1952).

7. A. R. Main, K. E. Miles and P. E. Braid, Biochem. J. 78, 769 (1961)

8. K. F. Bamford and H. Harris, Ann. hum. Genet. 27, 417 (1964).

9. H. Harris and M. Whittaker, Nature, Lond. 191, 496 (1961)

10. W. Kalow and H. A. Lindsay, Can. J. Biochem. Physiol. 33, 568 (1955).

11. C. Huggins and J. Lapides, J. biol. Chem. 170, 467 (1947).

12. P. W. Zapf and CH. M. Coghlan, Clinica. chim. Acta 44, 237 (1973).

13. O. Lockridge and B. N. La Du, J. biol. Chem. 253, 361 (1978).

14. O. Lockridge, H. W. Eckerson and B. N. La Du, J. biol. Chem. 254, 8324 (1979).

15. L. B. Hersh, P. P. Raj and D. Ohlweiler, J. Pharmac. exp. Ther. 189, 544 (1974).

16. O. Lockridge, N. Mottershaw-Jackson, H. W. Eckerson and B. N. La Du, J. Pharmac. exp. Ther. 215, 1 (1980).

17. R. B. McComb, R. V. La Motta and H. J. Wetstone, Clin. Chem. 11, 645 (1965).

18. H. Muensch, A. Yoshida, K. Altland, W. Jensen and H. W. Goedde, Am. J. hum. Genet. 30, 302 (1978).

19. H. M. Rubinstein, A. A. Dietz, T. Lubrano and P. J. Garry, J. med. Genet. 13, 43 (1976).

20. R. O. Davies, A. V. Marton and W. Kalow, Can. J. Biochem. Physiol. 38, 545 (1960).

21. F. F. Foldes, D. L. Davis, S. Shanor and G. Van Hees, J. Am. chem. Soc. 77, 5149 (1955).

22. M. Whittaker and C. A. Hardisty, Clin. Chem. 15, 445 (1969).

23. P. P. Raj, R. Rosenblatt, J. Miller, R. L. Katz and E. Carden, Anesth. Analg. 56, 110 (1977).

24. J. C. Smith and F. F. Foldes, Biochim. biophys. Acta 289, 352 (1972).

25. J. R. Downs, J. oral Surg. 24, 256 (1966).

26. J. Viby-Mogensen and H. K. Hanel, Acta anaesth. scand. 22, 371 (1978).

27. E. K. Zsigmond and T. E. Eilderton, J. oral Surg. 33, 833 (1975). 